\title{
THE EFFECT OF BEND ANGLE ON THE EVAPORATIVE COOLING OF AIR FLOW THROUGH BENT DUCT
}

\author{
Abdul Sattar Jawad Mohammed ${ }^{1}$ \\ asj_2006saraf@yahoo.com
}

\author{
Akeel Asie Nazzal ${ }^{2}$ \\ akeelakeel1992@gmail.com
}

${ }^{1,2}$ Mechanical Engineering Department, University of Technology, Baghdad

\begin{abstract}
One remediation to output power drop of a gas turbine generating units during hot climates is reducing compressor inlet air temperature using fogging technique incorporating water injection into the airstream. The inlet air ductworks often include a bend or curved duct before the compressor comprising the secondary flow utilized to enhance the mixing between air and water droplets. This study investigates the effect of changing the bend angle on the resultant evaporative cooling of steadily flowing airstream. The experiments were conducted with an average air velocity range from $(2.5$ to $5 \mathrm{~m} / \mathrm{s})$ through $(50) \mathrm{cm}$ square duct. The study considered three bend angles of $\left(45^{\circ}, 90^{\circ}\right.$ and $\left.135^{\circ}\right)$ along with three sets of nozzle tilt angles of $\left(-450,0^{\circ}\right.$ and $\left.45^{\circ}\right)$ to the axial flow direction. The results reveal that best evaporative cooling was achieved at a bend angle of $\left(135^{\circ}\right)$ when the water is axially injected, i.e., at (0o) to flow direction. These conditions were obtained at the velocity of $(2.5 \mathrm{~m} / \mathrm{s})$, giving enough residence time for the injected droplets to evaporate and cool the airstream.
\end{abstract}

Keywords: Curved duct; Bend angle; Compressor inlet air cooling; Fogging system.

\section{تأثثر زاوية الانحناء على التبريد التبخيري لتدفق الهواء عبر القتاة المنحنية \\ عبد الستار جواد محمد عقيل عاصي نزال}

تعتبر عملية تقليل درجة حرارة الهو اء لمدخل ضاغط التوربينات الغازية باستخدام تقنية توليد الضباب (Fogging)

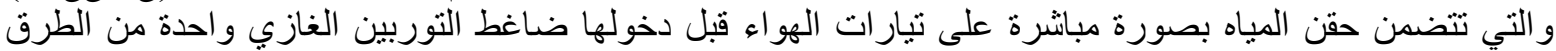

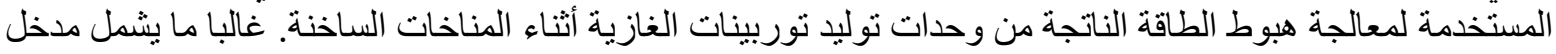

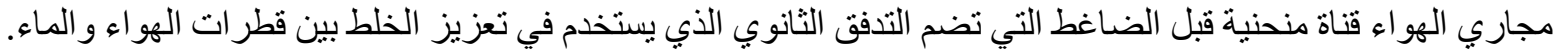

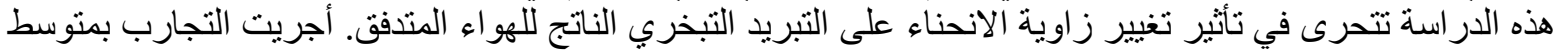

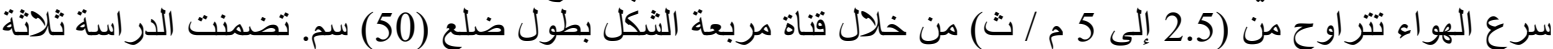

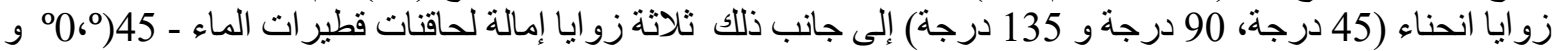

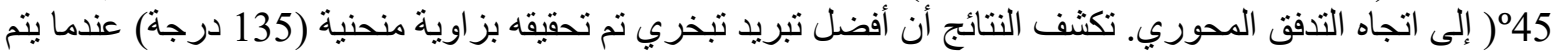
حقن الماء بشكل محوري، أبي في (0)

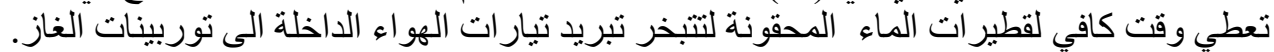


NOMENCLATURE

\begin{tabular}{|c|c|c|c|c|c|}
\hline $\mathrm{a}$ & Duct width & $\mathrm{m}$ & \multicolumn{3}{|c|}{ Dimensionless parameters } \\
\hline $\mathrm{b}$ & Duct height & $\mathrm{m}$ & Dn & Dean No. & $\operatorname{Re} \sqrt{D_{h} / K_{c}}$ \\
\hline $\mathrm{D}_{\mathrm{h}}$ & Hydraulic radius & $\mathrm{m}$ & $\operatorname{Re}$ & Reynolds No. & $\rho u D_{h} / \mu$ \\
\hline $\mathrm{R}_{\mathrm{c}}$ & Bend inner radius & $\mathrm{m}$ & $\beta$ & Vertical probe location & $\mathrm{Y}_{\mathrm{n}} / \mathrm{b}$ \\
\hline$\hat{\mathrm{R}}_{\mathrm{C}}$ & Mean bend radius & $\mathrm{m}$ & $\zeta$ & Horizontal probe location & $\mathrm{X}_{\mathrm{n}} / \mathrm{a}$ \\
\hline RH & Relative humidity & $\%$ & $\theta$ & Temperature & $\mathrm{T}_{\mathrm{n}} / \mathrm{T}_{\mathrm{amb}}$ \\
\hline $\mathrm{T}$ & Temperature & ${ }^{\circ} \mathrm{C}$ & $\psi$ & Relative humidity & $\mathrm{RH}_{\mathrm{n}} / \mathrm{RH}_{\mathrm{amb}}$ \\
\hline $\mathrm{u}$ & Velocity & $\mathrm{m} / \mathrm{s}$ & \multicolumn{3}{|c|}{ Subscript } \\
\hline$\phi$ & Nozzle tilt angle & $\operatorname{deg}$ & amb & Ambient & \\
\hline$\lambda$ & Bend angle & $\operatorname{deg}$ & ave & Average & \\
\hline$\rho$ & Density & $\mathrm{kg} / \mathrm{m}^{3}$ & $\mathrm{i}$ & At an element & \\
\hline$\mu$ & Viscosity & $\mathrm{Pa} \mathrm{s}$ & $\mathrm{n}$ & At a location & \\
\hline $\mathrm{X}$ & Horizontal location & $\mathrm{cm}$ & \multicolumn{3}{|c|}{ Abbreviation } \\
\hline Y & Vertical location & $\mathrm{cm}$ & CFD & \multirow{2}{*}{\multicolumn{2}{|c|}{$\begin{array}{l}\text { Computational Fluid Dynamics } \\
\text { Renormalized Group Analysis }\end{array}$}} \\
\hline Z & Axial location & $\mathrm{cm}$ & RNG & & \\
\hline
\end{tabular}

\section{INTRODUCTION}

Many engineering applications comprise fluid flow through pipes or ducts with various geometries that significantly affect the flow field structure. One of these common situations is the change in flow direction as crossing through a curved part of a duct. The most interesting feature in such a case is the secondary flow developed due to the imbalance between viscous forces and centrifugal forces. Vortices generated within the flow field help in agitating and mixing of the bulk of the fluid and can provide vigorous rates of energy and momentum exchange. Dean (1928) was mathematically demonstrating the existence of a pair of counterrotating vortices in fully developed turbulent flow through the bent duct. The calculation of turbulent flows is made using a two-equation turbulence model in a large curvature rectangular duct by Pratap et al. (1975). The momentum and heat fluxes for grid nodes adjacent to a wall were empirically prescribed by making a simple Couette-flow analysis. Boutabaa et al. (2009) performed a three-dimensional simulation of developing secondary flows of Newtonian and viscoelastic fluids through a square bend duct. Two steady Dean cells and four cells upstream were arising as the centrifugal forces remarkably increased. Turbulent flow in circular $90^{\circ}$ bend was studied by Sudo et al. (1998) and Dutta et al. (2014). Sudo experimentally obtained the full map of longitudinal, circumferential, and radial velocity components using a hot wire. On the other hand, the numerical investigation performed by Dutta draws the velocity fields of primary and secondary flows and the turbulent intensity at different locations. The induction of secondary flow was demonstrated due to fluid transportation from the inner to the outer wall causing flow separation. Many researchers investigated the effect of secondary flow on heat transfer in bend ducts. The numerical simulation for the externally heated rectangular bend of the aspect ratio of 8 for Dean Numbers between 20 and 500 was done by Tilak et al. (2003), showing the strong mutual influence between heat transfer and secondary motion. Nevertheless, Arvanitis et al. (2018) 
studied the heat transfer characteristics numerically in U-bend for partial and full curvature showing an overshoot of the downstream/upstream Nusselt number ratio at the entrance region.The dominant effect in bends flow is the pressure drop resulting from severe turbulences developed. Mondol et al. (2018) investigated using ANSYS-FLUENT software the laminar fully developed with the no-slip condition for different bend angles. Results reveal that the less $90^{\circ}$ bend angle is superior in pressure drop characteristics over $90^{\circ}$ and greater bend angle and has the highest inlet pressure, making it suitable for fluid convey. However, using a single guide vane reduces pressure drop by 50\%, as per Shabani et al. (2019). Nevertheless, using two guide vanes may attain more than 50\% reduction in pressure drop. The structure of the secondary motion was proved to be influenced strongly by the curvature ratio of the bend. The numerical study of Dutta et al. (2018) deals with separation reattachment flow under high Reynolds numbers in $90^{\circ}$ circular bend with different bend curvatures. They clearly stated that separation is caused by the drift of fluid from the inner to the outer wall of the bend. Norouzi et al. (2013), on the other hand, investigated the incompressible flow through curved ducts with a rectangular cross-section. The analytical solution gave the distribution of main flow and secondary flow as well as the resistance ratio. The effect of curvature and aspect ratios was proven through the perturbation method. Mohammed et al. (2020) study the impact of bend curvature on flow structure and turbulence intensity using the experimental Particle Image Velocimetry (PIV). Results indicate four cells pattern in $90^{\circ}$ square bend. The pair close to the inner wall moves outwards to the outer wall, decreasing curvature ratio due to flow separation and growth in centrifugal effects. Turbulences and secondary motion significantly influence the rate of mixing and penetration of dispersed phases within a continuous flow. This process encourages mass and heat transfer and hence the evaporation of tiny liquid droplets being introduced into a gas stream. This phenomenon has been studied by many researchers to deal with the spray dynamics and measurement included in fogging technique representing a promising method of compressor inlet air cooling in gas turbine power plants. Fogging method has the vantage of simple construction and fewer modifications to the original plant. Cooling of inlet air would compensate for the drop in power output during hot climates due to decreased air density and the airflow rate of mixing the inlet air and evaporative water droplet. Chaker et al. (2002) led a comprehensive study of the characteristics of the fogging method, including droplet heat transfer. Extension to their work, they investigate the droplets sizing and measurements Chaker et al. (2004). Furthermore, they studied the droplet behavior in the inlet ducts and the extensive implementation of fogging systems in several gas turbine power plants Chaker et al. (2004). In that context, Ahmed et al. (2013) explored the results of the experimental study on spray characteristics of water within a $90^{\circ}$ curved square duct, including the optimum position of the atomizer defined by ratio $\left(\mathrm{r} / \mathrm{r}_{\mathrm{in}}\right)$ of 3.2 and orientation of $-10^{\circ}$ to the axial flow direction giving a temperature reduction of $39.6 \%$. Mohammed et al. (2018) experimentally complete this effort by spraying water downstream the curved duct and obtained $26 \%$ reduction in temperature for an atomizer position of $r / r_{\text {in }}$ ratio of 3 when injecting water axially with the flow direction. The droplet coalescence in miter L shape duct was numerically simulated by Hamandi et al. (2015). The simulation focused on the droplet 
coalescence at the intake of a gas turbine engine with fogging implementation. The results showed that $\mathrm{L}$ shape encourages coalescence due to the drift beyond the miter edge, and hence, larger droplets are formed, and poor droplets evaporation and falling off are expected. Mohammed et al. (2020) experimentally and numerically investigated the impact of duct curvature on the humidification of air passing through the square $90^{\circ}$ bend duct by injecting water before the bend. The study considered three different curvature ratios, in addition to characterizing the injector position concerning the flow. Results revealed that injecting water axially to the flow at three hydraulic diameters upstream of the bend with 0.75 curvature ratio would bring $17 \%$ reduction in air temperature. They attributed that to the shrink in the separation zone accompany the weakening of centrifugal forces. The geometry of the bend is greatly influenced the flow field and the rates of heat and mass transfer. This study is motivated to investigate both experimentally and numerically the effect of changing bend angle on the evaporative cooling of steady turbulent airflow through the square duct. It is considered a simulation of the fogging process applied to the compressor inlet air in a gas turbine engine aiming the boost power output.

\section{EXPERIMENTAL SETUP}

The experimental test rig used in the study is a $50 \mathrm{~cm}$ square duct comprising multiple parts with each devoted for a specified task, as shown in figure(1). The air is induced into the duct through a bell mouth profiled part such that to diminish the inlet disturbance to the flow. The properties of the induced air are fixed with the aid of electric heaters and steam humidifier installed in a first straight part of $3 \mathrm{~m}$ long comes after the bell mouth. The supposed constant ambient condition throughout experiments must be kept at $45^{\circ} \mathrm{C}$ and $15 \%$ relative humidity. Tiny water droplets are introduced into the airstream by a mist generator that can move axially before a bent part of the duct. Distilled water is supplied to the $0.1 \mathrm{~mm}$ diameter water injectors under a pressure of 70 bar by an instrumented pumping machine (model AG-801003 800w Mini Fog Machine Electric Ulv Cold Fogger), as shown in figure(2). These injectors can rotate in an angular range from $\left(90^{\circ}\right.$ to $\left.-90^{\circ}\right)$ around the flow direction. Three bends were manufactured with different bend angles $45^{\circ}, 90^{\circ}$, and $135^{\circ}$, as depicted in figure(3). These configurations intend to use the secondary motion within the bend to distribute and mix the injected water droplets with the air stream. Downstream the bend, a second $3 \mathrm{~m}$ straight part of the duct is connected to the inlet of the axial fan such that the treated air is exhausted out the test rig. A double butterfly gate was installed at the fan exit to control the amount of airstream induced into the rig. The air velocity is measured with a Pitot-static tube settled at the beginning of the first straight duct. ARDUINO system comprises 25 probes to record air temperature and relative humidity across the duct cross-section before the fan inlet such that these records are sent to PC to be saved and processed later, see figure(4). Induced airstream properties are recorded by four probes that are installed directly after the heating and humidification section to assure the constant supposed ambient condition.

\section{NUMERICAL APPROACH}

The Commercial package ANSYS FLUENT 19.R1 was chosen to study the airflow structure numerically and the secondary motion generated due to the flow through a $50 \mathrm{~cm}$ 
square bend. A discrete phase model is used to analyze for water introduction into the air stream. Three-dimensional flow in RNG k- $\varepsilon$ the turbulent model was employed in the study with the geometry shown in figure(5). As listed in Table (1), three air velocities were used, which are chosen to study the effect of changing Reynold number, bending angle, and the nozzles tilt angle on the flow structure and mixing process.

The following practical assumptions of the physical model were assumed to carry out the CFD simulations using ANSYS FLUENT program:

- Steady-state

- Turbulent flow.

- Newtonian fluid.

- Incompressible.

- Three-dimensional.

- The air continuous flow is treated as a single-phase homogeneous.

-Water is treated as a discrete phase flow.

The simulation was used to solve the conservation equations of mass, momentum, energy, and moisture by means of the finite volume method to determine the velocity fields, temperatures, and other parameters characterizing the air.

$>$ Mass conservation

$$
\frac{\partial}{\partial x_{j}}\left(\rho_{f} U_{f j}\right)=0
$$

Momentum conservation

$$
\frac{\partial\left(\rho_{f} U_{f i} U_{f j}\right)}{\partial x_{i}}=-\frac{\partial(p)}{\partial x_{i}}+\frac{\partial}{\partial x_{i}}\left(\mu \frac{\partial U_{f i}}{\partial x_{j}}-\overline{U_{f i} U_{f j}}\right)
$$

Energy equation

$$
\frac{\partial}{\partial x_{j}}\left(\rho_{f} U_{f j} T_{f}\right)=\frac{\partial}{\partial x_{j}}\left[\left(\rho_{f} \alpha_{t}+\frac{\mathrm{k}_{f}}{C_{p f}}\right) \frac{\partial T_{f}}{\partial x_{j}}\right]
$$

The models used in FLUENT, depending on the average time with modified equations, include unknown variables. To determine these variables in known quantities, turbulence models are needed. The considerations for turbulence model choice depend on the physical properties included in the flow, the used practice for a specific type of problem, the requirement of accuracy, computational resources, and simulation time Abramzon et al. (1988), Collin (2007). The standard model of k- is used in this study. The turbulence kinetic energy and dissipation rate are obtained from the following transport equations based on Mon Soe (2017), Cable (2009).

$$
\begin{aligned}
& \frac{\partial}{\partial t}\left(\rho_{f} \mathbf{k}_{f}\right)+\frac{\partial}{\partial x_{j}}\left(\rho_{f} \mathbf{k}_{f} U_{f i}\right)=\frac{\partial}{\partial x_{j}}\left[\left(\alpha_{k} \mu_{e f f}\right) \frac{\partial \mathbf{k}_{f}}{\partial x_{j}}\right]+G_{k}+G_{b}-\rho_{f} \varepsilon_{f}-Y_{M}+S_{k} \\
& \frac{\partial}{\partial t}\left(\rho_{f} \varepsilon_{f}\right)+\frac{\partial}{\partial x_{j}}\left(\rho_{f} \varepsilon_{f} U_{f i}\right)=\frac{\partial}{\partial x_{j}}\left[\left(\alpha_{\varepsilon_{f}} \mu_{e f f}\right) \frac{\partial \varepsilon}{\partial x_{j}}\right]+C_{1 \varepsilon_{f}} \frac{\varepsilon}{\mathbf{k}_{f}}\left(G_{k}+G_{3 \varepsilon} G_{b}\right)-C_{2 \varepsilon_{f}} \rho_{f} \frac{\varepsilon_{f}^{2}}{\mathbf{k}_{f}}+S_{\varepsilon_{f}}
\end{aligned}
$$


For design consideration, the optimum configuration of the injection matrix was chosen in accordance with the numerical simulation performed. Three configurations were suggested, as depicted in figure(6), with the injectors superimposed on the vortices generated within the bend to consider the optimum air cooling and adopted throughout the experiments. The structure of the secondary motion and the vortices developed were processed using particle image Velocimetry PIV technique in MATLAB (PIVlab) introduced by Thielicke and Stamhuis (2014). Metal particles ejected out of the seeding system are illuminated by a $2 \mathrm{~mm}$ thick laser sheet, while a high-speed camera is used to capture images of the flow field, see figure(7). Small sub-images of a particle between two successive points are processed by MATLAB to determine the displacement during a prescribed time interval providing the velocity vectors for the whole flow field.

\section{RESULTS AND DISSECTION}

The first part is devoted to choosing the superior injectors' configuration, which conforms to the flow structure to give the utmost cooling. Whence figures(8) through (10) show the results of the numerical analysis indicating that the equally spaced injectors $C_{1}$ is the best configuration among the three given in figure(6). That because it gives the lowest average air temperature at all three bend angles, whatever the injector tilt angle is. The relative velocity between the water droplet and the surrounding air has a significant effect on the water evaporation rate. As the water flow rate is constant, so is the droplet velocity ejected out the injector. Therefore, the relative velocity is the function of the airstream velocity, and lower air velocity gives longer residence time for the droplet to exchange energy with the air and evaporate. This is clearly indicated in figure(11), in which velocity $2.5 \mathrm{~m} / \mathrm{s}$ produce the lowest temperature compared to velocities 3.75 and $5 \mathrm{~m} / \mathrm{s}$ for humidified air traveling through $90^{\circ}$ bend duct. However, bend angle strongly affects the local temperature distribution across the duct and the average air temperature at the main test section. Figure(12) shows a contour drawing of temperature for bend angle of $45^{\circ}$ at different injector tilt angles. If water is sprayed towards the inner wall, i.e., at $-45^{\circ}$, most of the droplet travel along the inner wall and separation zone, making the outer half almost dry and hot. This effect will yield a relatively high average temperature at the test section due to the delayed mixing of cold and hot streams. On the other hand, injecting water axially along the flow direction at $0^{\circ}$ will give a better spread of droplets. They rotate with secondary motion into the inner half but with the major portion traveling along the outer half. This would provide good stream mixing and hence, lower relatively air temperature. The worse scenario is observed with water injected towards the outer wall at $+45^{\circ}$ tilt angle as most of the droplets trapped away from the separation zone, making the inner half totally dry till the end of the duct. Thus, the average air temperature, in this case, is the highest. In the case of $90^{\circ}$ bend, as figure(13) reveals, at a tilt angle of $-45^{\circ}$, the bulk of the water droplets going along the inner wall and spread towards the outer half downstream the bend. However, a layer of hot non-humidified air travels in the vicinity to the outer wall and misses to mix with the colder stream till the end producing a high average temperature there. Nevertheless, if water is injected axially, the droplets spread almost evenly at the entry to the bend, but most are drifted towards the outer half downstream. 
However, the rest of the droplets kept within the separation zone evaporate and mixed with the cold air comes along the outer half producing lower temperature at the test section. Again, the situation with $+45^{\circ}$ injection is the worst as most of the water is directed to the outer wall leaving the inner half hot and dry. The little portion of the water rotates with inner vortices cause a slight cooling when it moves downstream. Beyond the separation zone when lately the two streams met, poor cooling is observed due to the weakening of vortices at the end of the duct. It is expected then; the average air temperature will be higher than the other tilt angles. Figure(14) shows the temperature contours of the treated air flowing into $135^{\circ}$ bend. The strong turn of the airstream gives a distinct behavior of droplets entrained with the air. When tilting the injector to the angle of $-45^{\circ}$, the droplets spread out downstream the bend, covering most of the cross-section, and better cooling is recorded at the end of the duct. However, injecting water at $0^{\circ}$, makes the entire bend inlet receive droplets, and good mixing is evident as both halves of the duct are cold and well humidified. This situation yields the lowest temperature ever recorded through this study. Referring to figure 14, it is clear that water injection towards the outer wall brings most of the droplets to move along the outer half, with the inner half remains almost non-humidified. A streak of cold air escaping out the separation zone is expected to mix with the large mass of cold air coming along the outer wall. Whence, slight cooling is observed at the end of the duct, where vortices weaken. It is worth pointing out the repeated phenomena in figures 11 through 14, indicating the concentration of lower temperature contours at the lower half of the duct. This is attributed to the gravity effect on the relatively large droplets that descend towards the bottom wall and last long enough to exchange heat with the air and get cooled. The optimum bend angle of the bend duct that gives the utmost reduction in treated air temperature can be obtained out of figure 15 . The figure reveals that the temperature reduction is about $16 \%$ for a bend angle of $135^{\circ}$, which excels $90^{\circ}$ and $45^{\circ}$ nearly by $3 \%$ and $6 \%$, respectively. The bend angle $135^{\circ}$ is then considered as the recommended bend geometry among the three angles studied. This is attributed to the identical four cells developed in secondary flow at higher Dean Number with almost equal turbulent strength. This effect would produce high agitating in the flow field and entraining more droplets within the vortices, which increase the rate of evaporation. An optimum position of mist generator (Fogging matrix) defined by $0^{\circ}$ injector tilting angle at three hydraulic diameters prior to the bend is a stipulation of such supreme performance. The feasibility of using bends to improve evaporative cooling of an airstream flowing through a duct appears in figure 16. It is clear that at any velocity of the airstream, the bent flow cooling transcends that in straight ducts due to the natural turbulences accompanied with the secondary motion. The $135^{\circ}$ bend duct gives $7 \%$ more temperature reduction as an average in comparison to the straight duct. A comparison under the same operating conditions is performed in figure 17 with the work of Mohammed and Sadiq (2020). The average transverse temperature distribution in both works is nearly the same as the difference never exceeds $2 \%$ on average. The figure revealing that in $90^{\circ}$ bend with $0^{\circ}$ tilted injector, the inner half of the duct is less susceptible to the whirl transported downstream. 


\section{CONCLUSIONS}

The main conclusions extracted from the study of the effect of changing the bend angle on the evaporative cooling of airstream going through the curved portion of a square duct can be summarized by:

- More residence time available for the droplets to exchange heat and mass with the surrounding air motivates the cooling. Hence, the air velocity of $2.5 \mathrm{~m} / \mathrm{s}$ is preferable in accordance with cooling characteristics.

- Injecting water towards the inner or the outer wall brings lower cooling extent due to the poor mixing and evaporation of water droplets. This fact applies to all bend angles.

- Axial water injection at $0^{\circ}$ tilted injector provides the highest temperature reduction of the treated air for all bend angles and promising the optimum position of the water injectors.

- The favorable bend geometry observed is when the curved duct has a $135^{\circ}$ bend angle giving the utmost cooling of about $16 \%$, and excels the other angle of $45^{\circ}$ and $90^{\circ}$ of about $6 \%$ and $3 \%$, respectively.

- The recommended configuration of a fogging system is defined by injection orientation of $0^{\circ}$ to the flow direction through $135^{\circ}$ bent duct

Table 1. List of flow conditions investigated in the current study

at $\mathrm{T}_{\mathrm{d}}=45^{\circ} \mathrm{C}, \mathrm{RH}=15 \%$

\begin{tabular}{|c|c|c|c|c|}
\hline Test No. & $\mathrm{U}_{\mathrm{ava}}(\mathrm{m} / \mathrm{s})$ & Reynolds number & Bend angle $\lambda$ & Investigated \\
\hline Run 1 & 5 & $14.3 \times 10^{4}$ & \multirow{3}{*}{$45^{\circ}$} & Experimental \\
\hline Run 2 & 3.75 & $10.73 \times 10^{4}$ & & + \\
\hline Run 3 & 2.5 & $7.15 \times 10^{4}$ & & Numerical \\
\hline Run 4 & 5 & $14.3 \times 10^{4}$ & \multirow{3}{*}{$90^{\circ}$} & Experimental \\
\hline Run 5 & 3.75 & $10.73 \times 10^{4}$ & & + \\
\hline Run 6 & 2.5 & $7.15 \times 10^{4}$ & & Numerical \\
\hline Run 7 & 5 & $14.3 \times 10^{4}$ & \multirow{3}{*}{$135^{\circ}$} & Experimental \\
\hline Run 8 & 3.75 & $10.73 \times 10^{4}$ & & + \\
\hline Run 9 & 2.5 & $7.15 \times 10^{4}$ & & Numerical \\
\hline
\end{tabular}




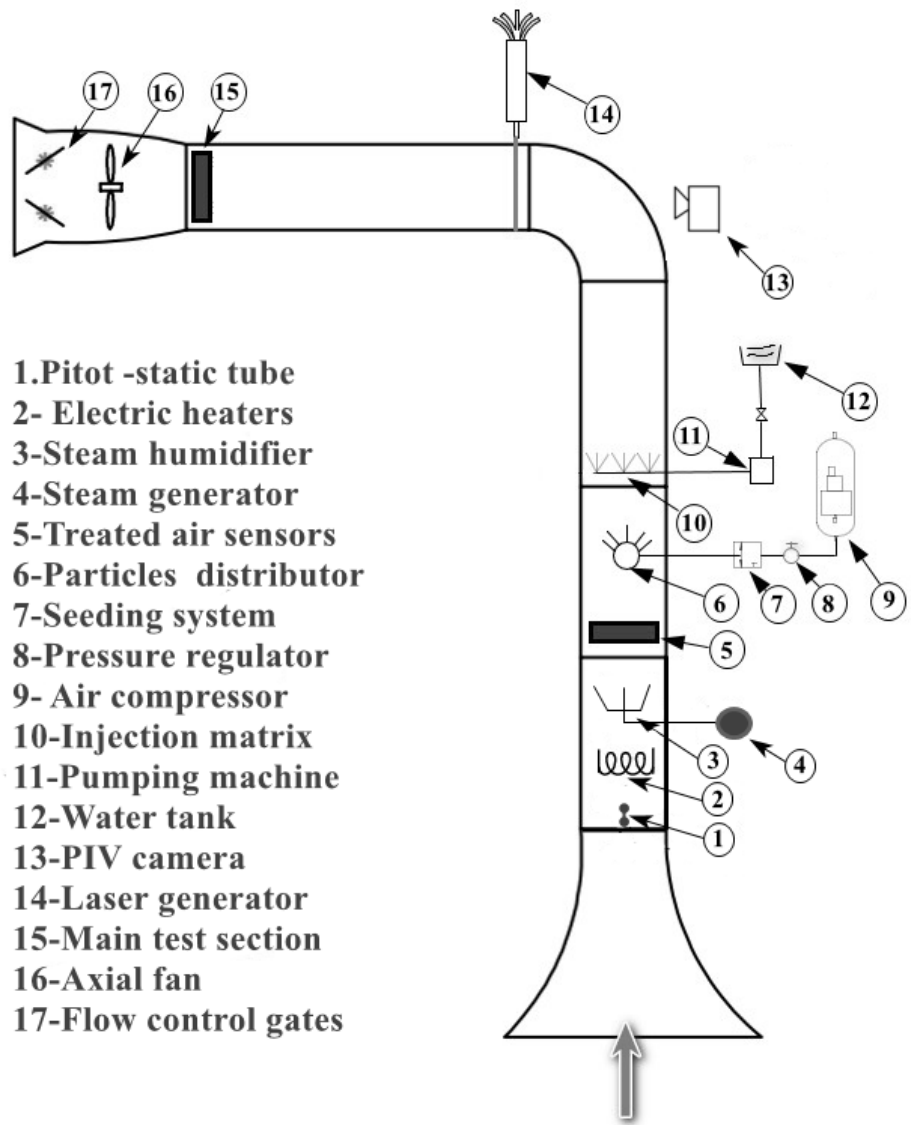

Air flow direction

Fig. 1. Schematic diagram of the test rig.

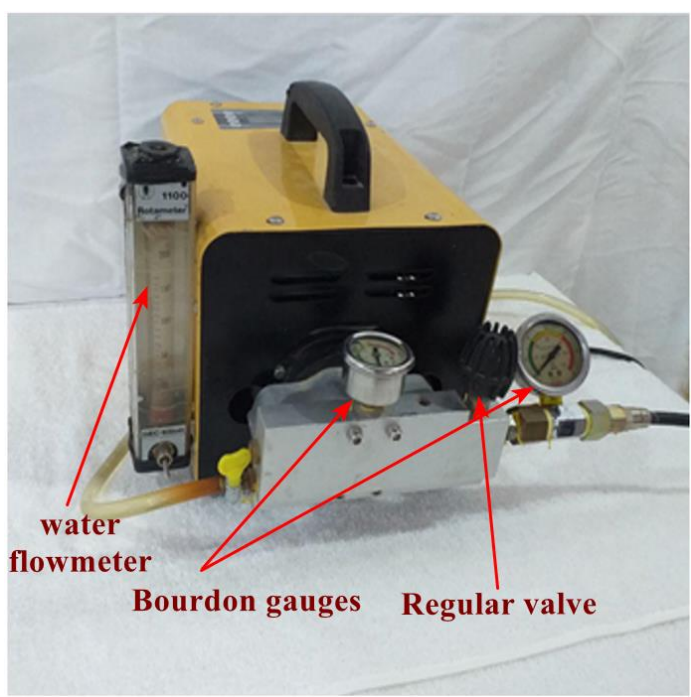

Fig. 2. Instrumented Water pump. 

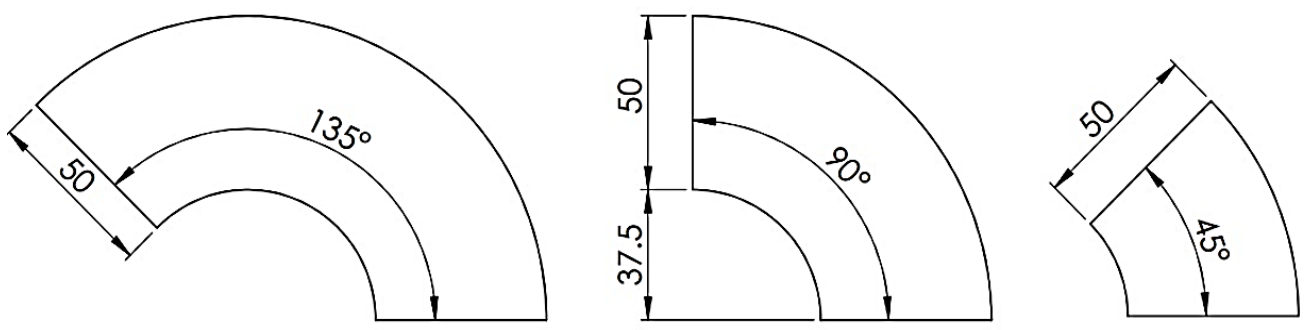

Fig.3. Three bent ducts with different bend angles at a curvature ratio of 0.75

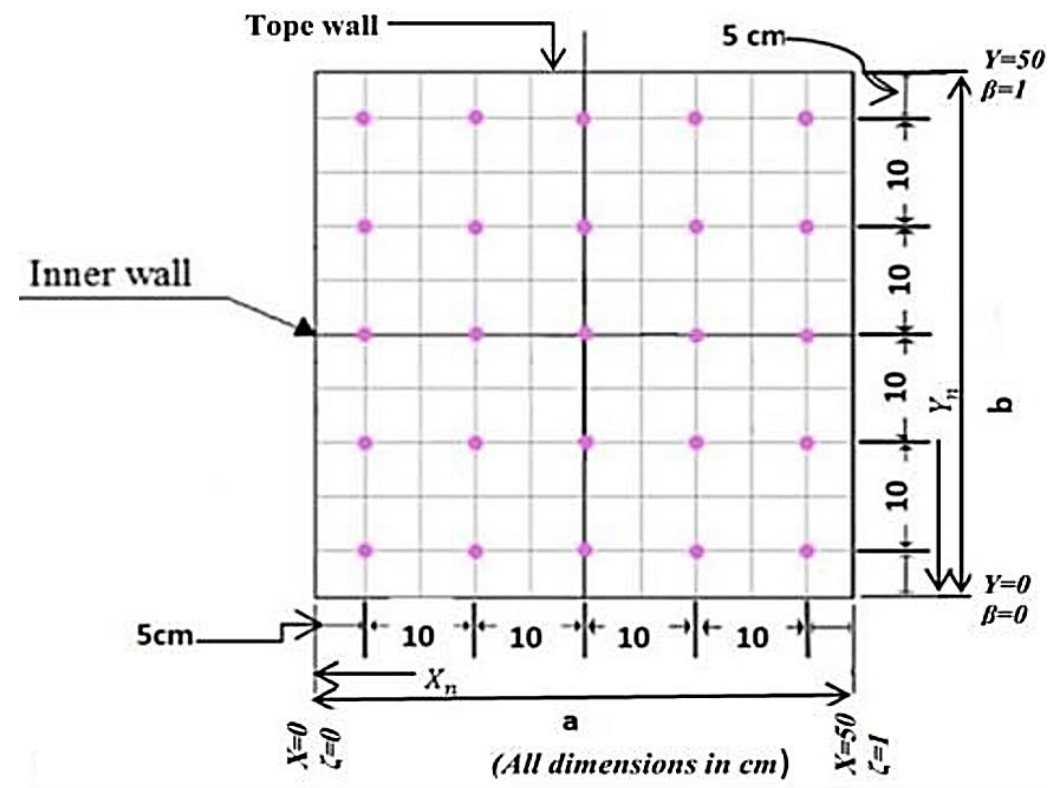

Fig.4. ARDOUINO sensors linked to data acquisition system on PC

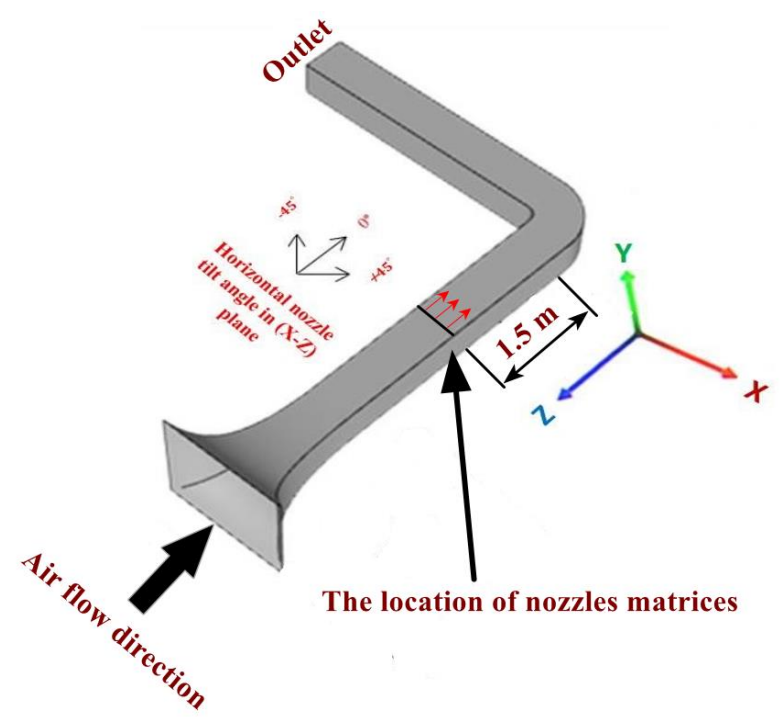

Fig.5. Coordinate system of the test rig showing the orientation of water injection and axial slide of injectors' matrix. 


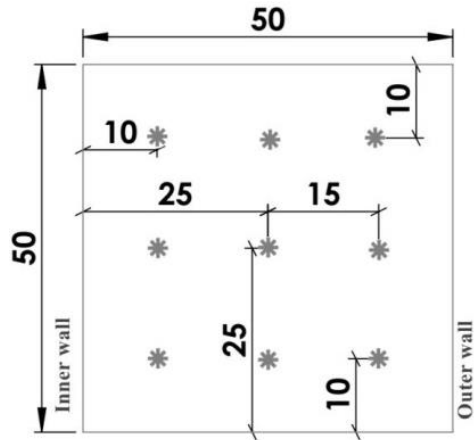

(a)

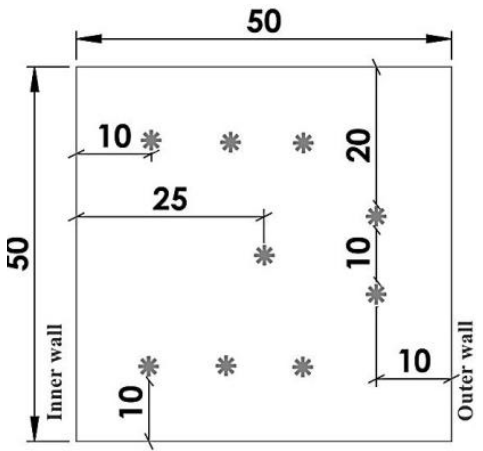

(b)

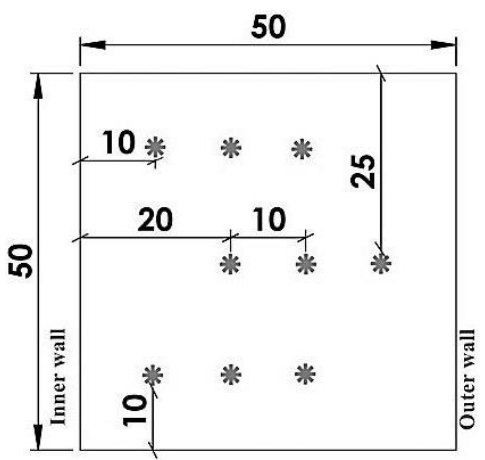

(c)

Fig.6. Suggested configurations of injection matrix superimposed on vortices developed in the flow field (All dimensions in $\mathrm{cm}$ ): (a) $\mathrm{C} 1$, (b) $\mathrm{C} 2$, (c) $\mathrm{C} 3$

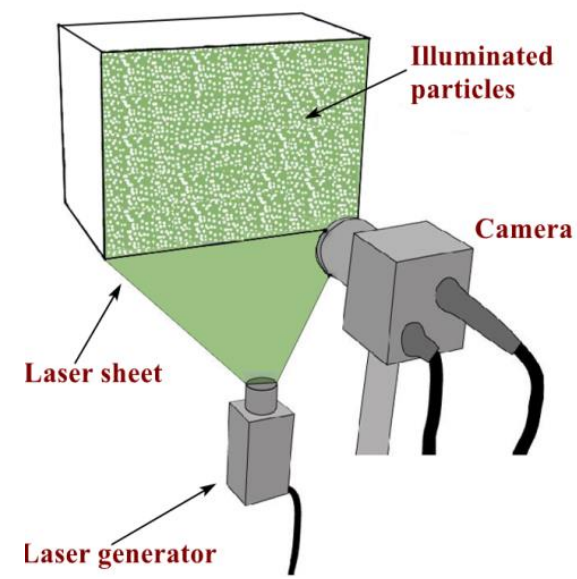

Fig.7. PIV system for particles image capture 


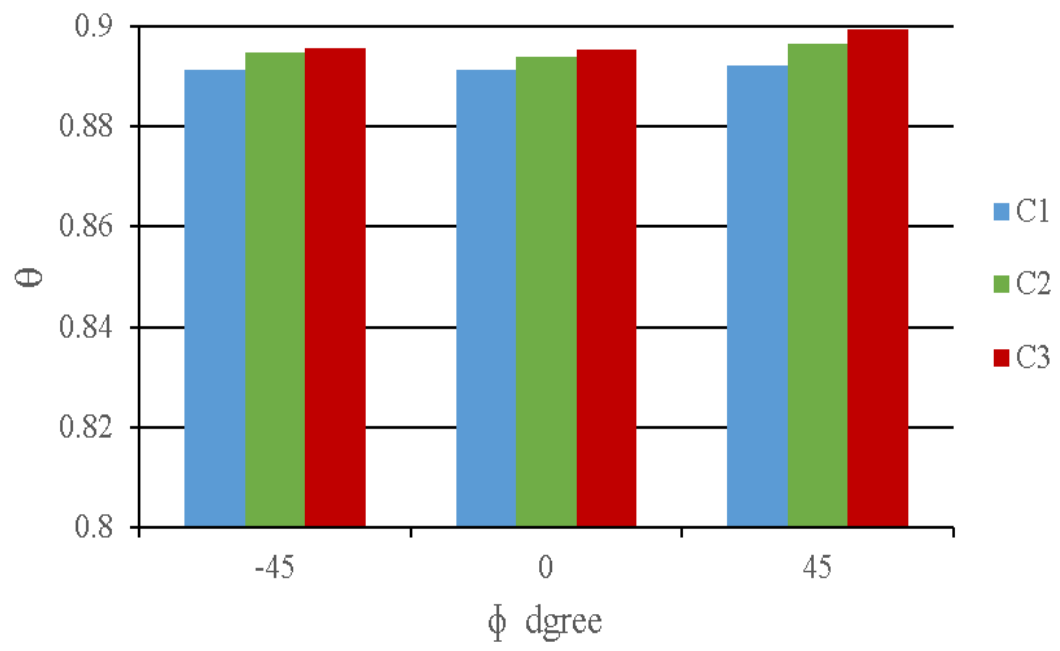

Fig. 8. Variation of dimensionless temperature with different nozzle array configurations at varying injector tilt angles for the $45^{\circ}$ bend.

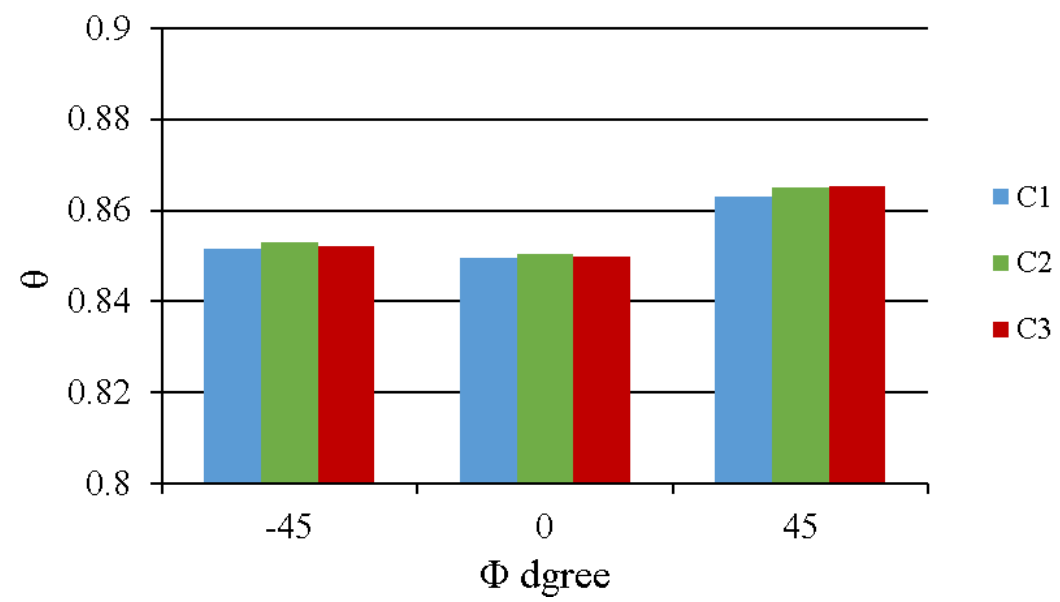

Fig. 9 Variation of dimensionless temperature with different nozzle array configurations at varying injector tilt angles for the $90^{\circ}$ bend.

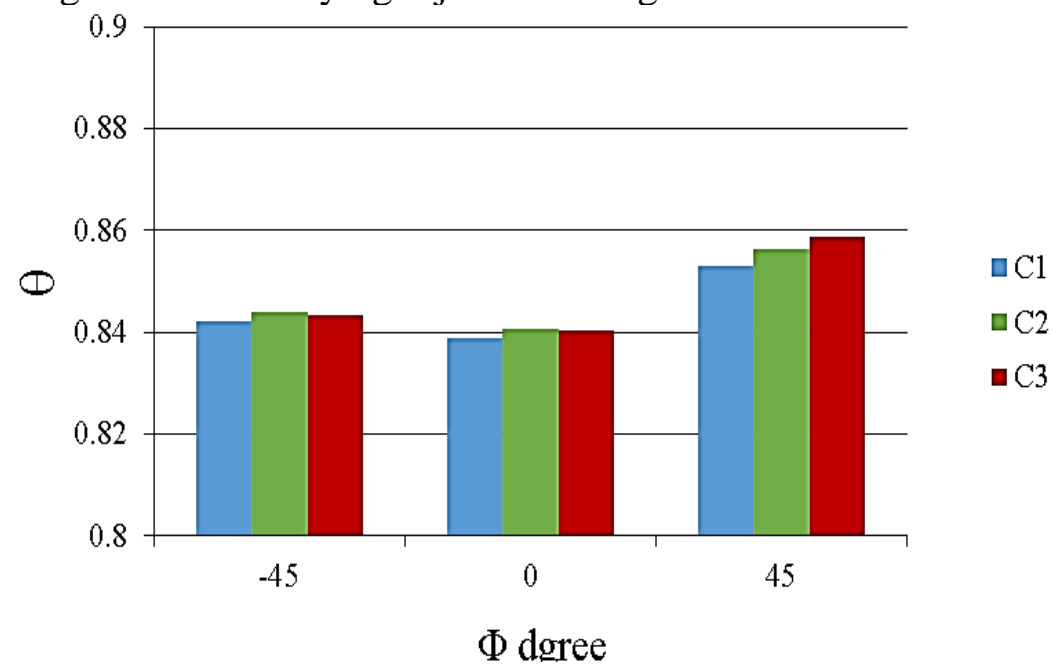

Fig. 10. Variation of dimensionless temperature with different nozzle array configurations at varying injector tilt angles for the $135^{\circ}$ bend. 


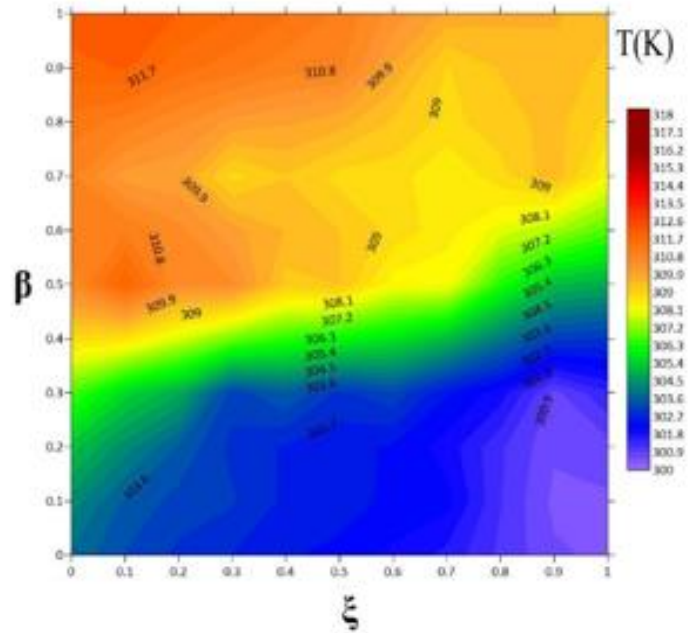

(a)

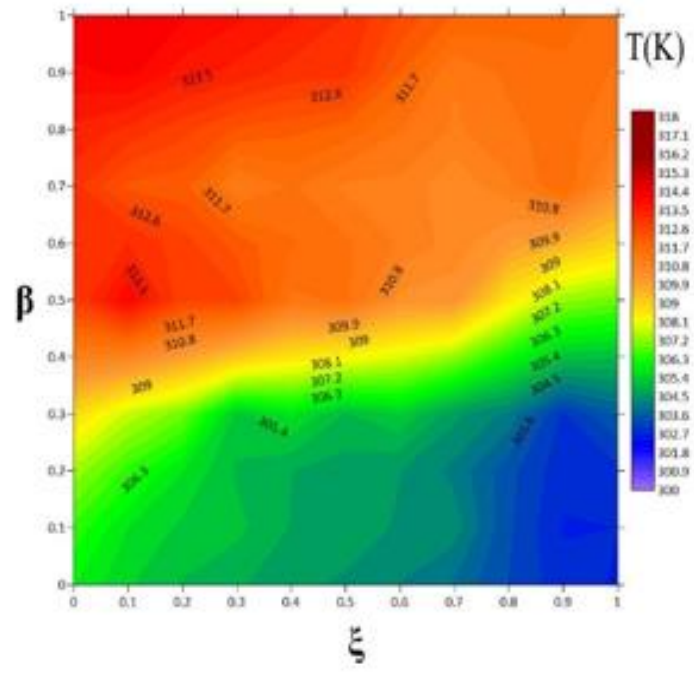

(b)

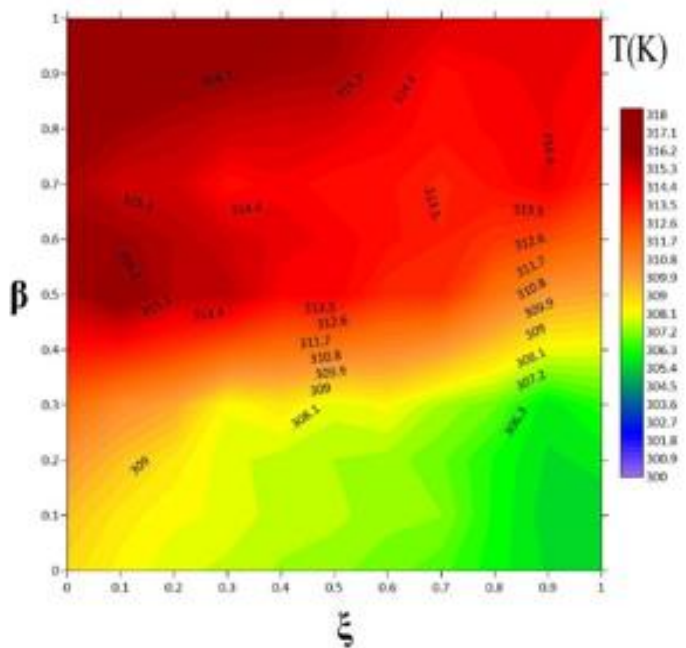

(c)

Fig. 11. Contour drawing of air temperature for $90^{\circ}$ bend duct at different air velocity:

(a) $2.5 \mathrm{~m} / \mathrm{s}$, (b) $3.75 \mathrm{~m} / \mathrm{s}$, (c) $5 \mathrm{~m} / \mathrm{s}$ at the outlet of the duct. 


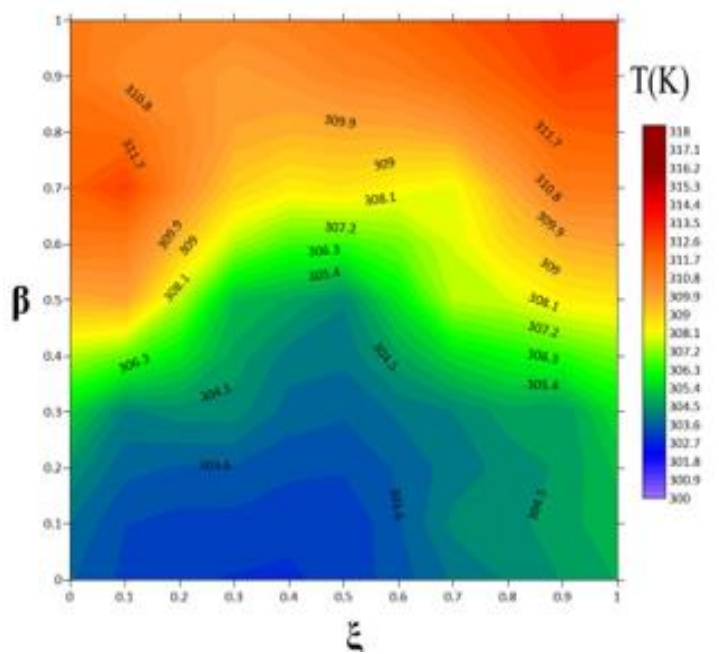

(a)

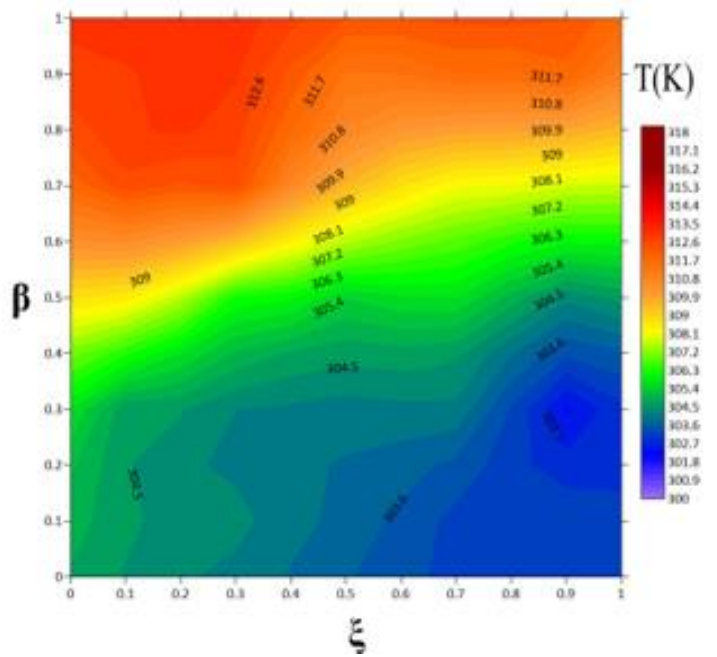

(b)

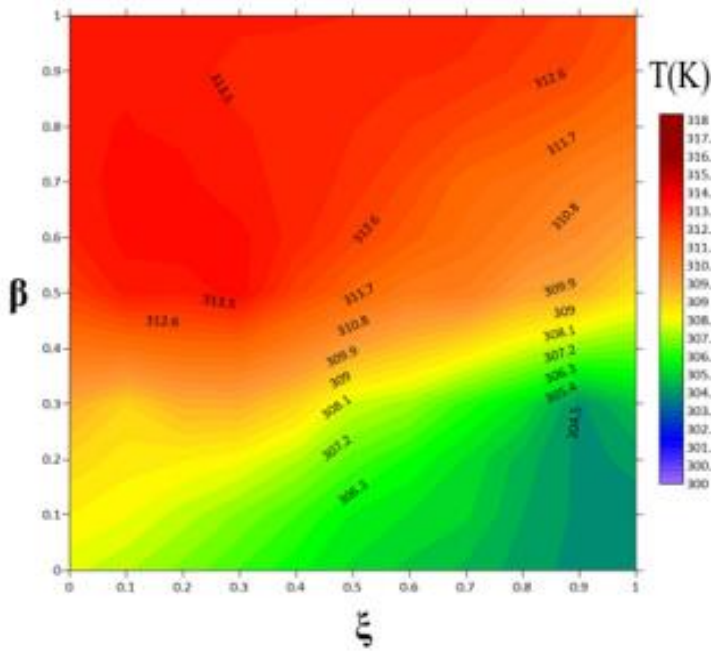

(c)

Fig.12. Contour drawing of air temperature for $45^{\circ}$ bend at different injector tilt angle:

(a) $-45^{\circ}$, (b) $90^{\circ}$, (c) $135^{\circ}$ at the outlet of the duct. 


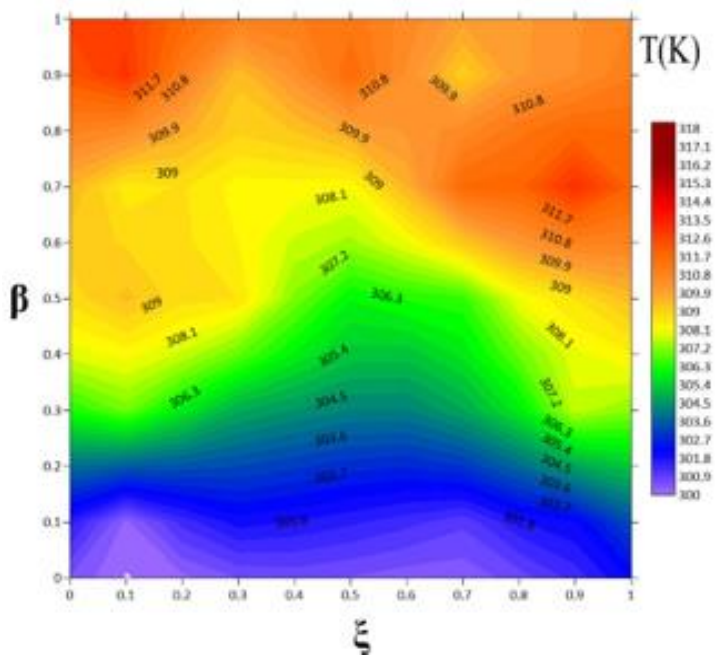

(a)

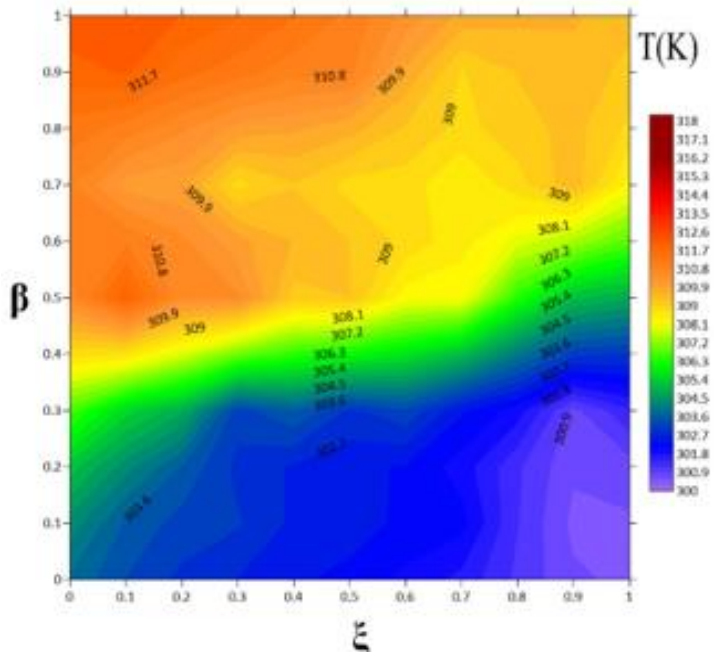

(b)

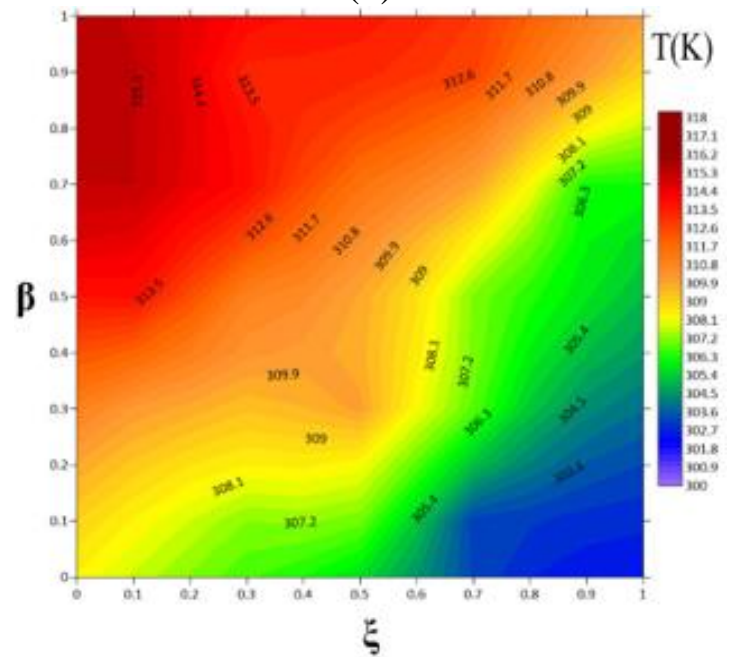

(c)

Fig.13. Contour drawing of air temperature for $90^{\circ}$ bend at different injector tilt angle:

(a) $-45^{\circ}$, (b) $90^{\circ}$, (c) $135^{\circ}$ at the outlet of the duct. 


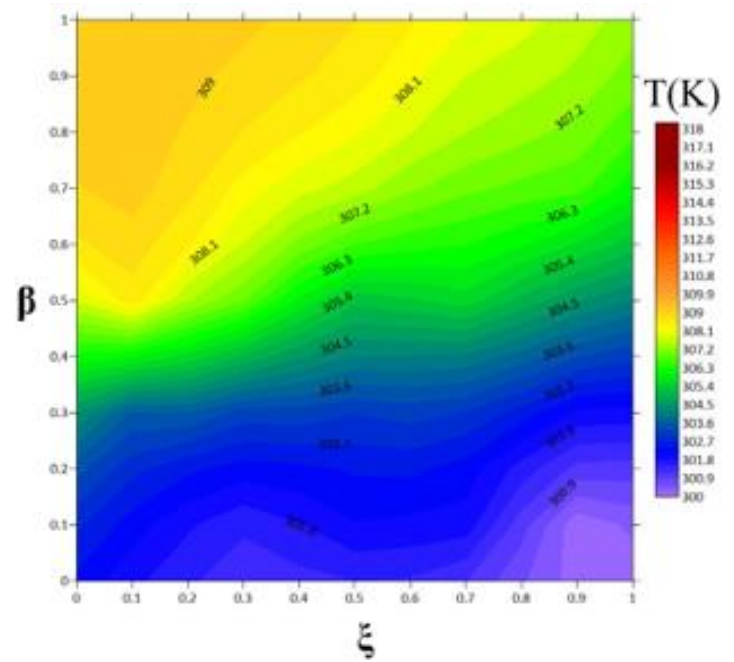

(a)

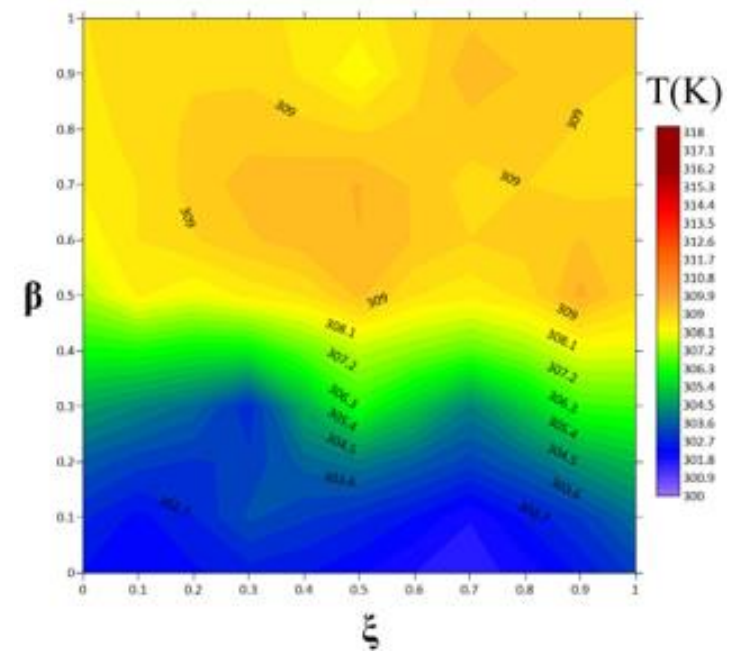

(b)

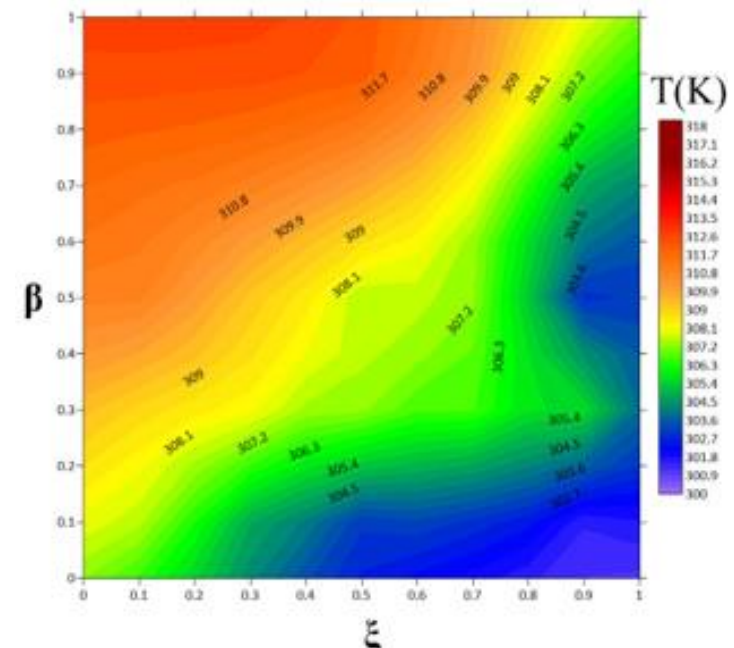

(c)

Fig.14. Contour drawing of air temperature for $135^{\circ}$ bend at different injector tilt angle:(a) $-45^{\circ}$, (b) $90^{\circ}$, (c) $135^{\circ}$ at the outlet of the duct. 


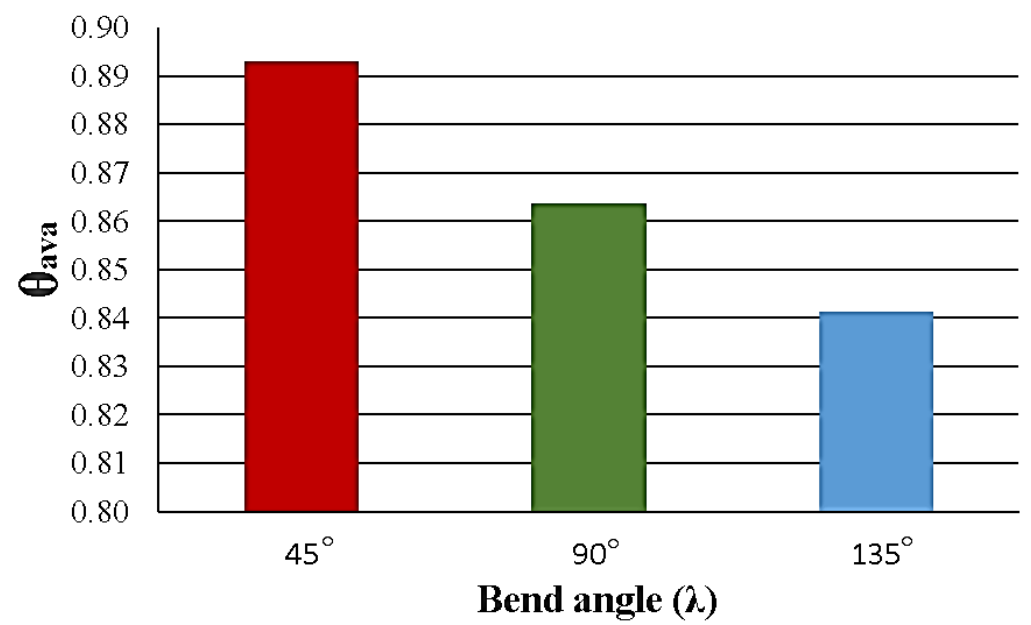

Fig.15. Variation of average dimensionless temperature for $135^{\circ}$ bend with $0^{\circ}$ injector tilt angle at $2.5 \mathrm{~m} / \mathrm{s}$ air velocity

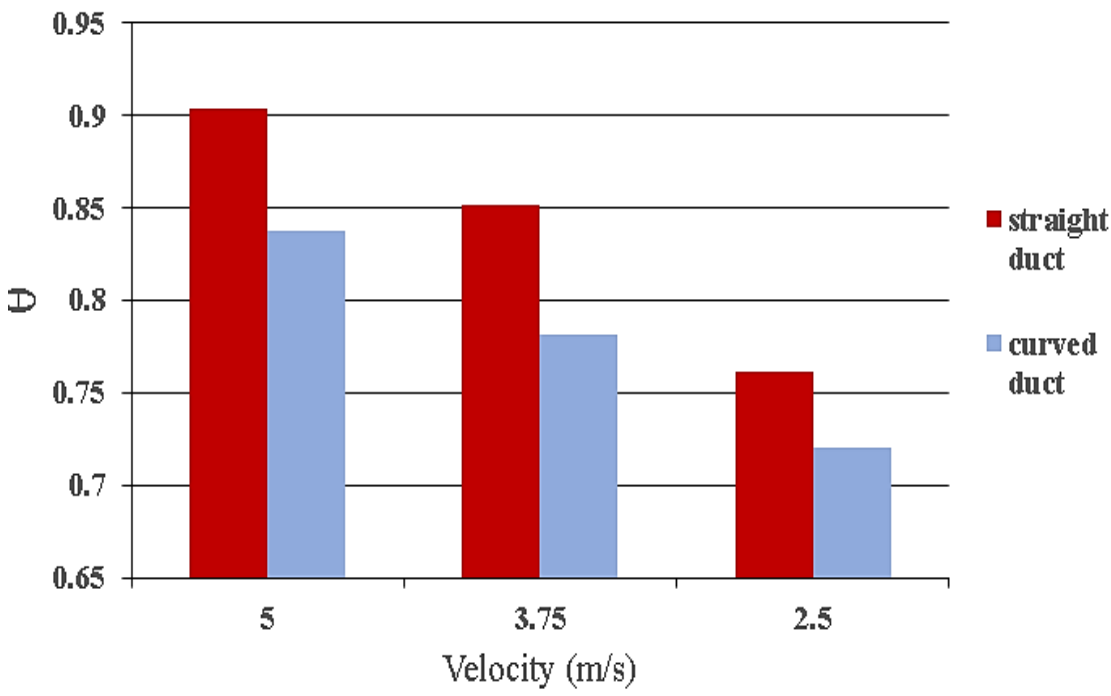

Fig.16. Comparison between the straight duct and $135^{\circ}$ bend duct with $0^{\circ}$ injector tilt angle

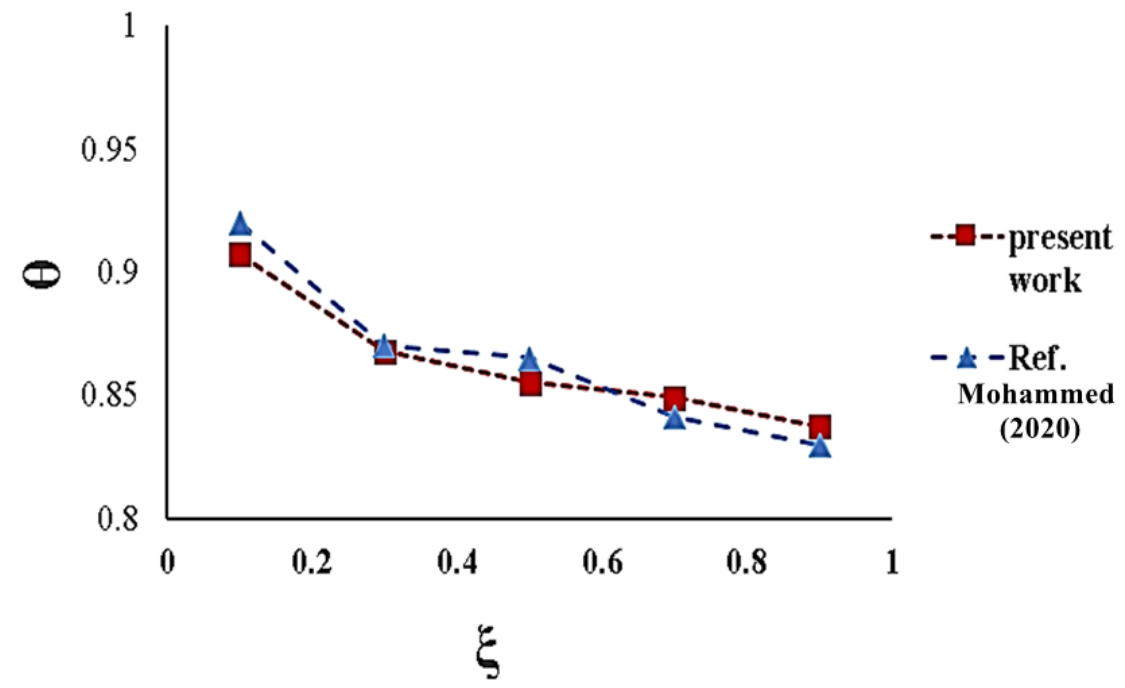

Fig.17. Comparison of transverse dimensionless temperature between present work and work of Mohammed et al. (2020) in $90^{\circ}$ band and $0^{\circ}$ injector tilt angle 


\section{REFERENCES}

Arvanitis et al., "Laminar flow and heat transfer in U-bends: The effect of secondary flows in ducts with partial and full curvature", International Journal of Thermal Sciences, Vol.130, 2018.

Ahmed et al. "The effect of atomizer position in a curved duct on the humidification process of steadily flowing air", Engineering \& Technology Journal,Vol 31, A, No.5, 2013.

Abramzon and W. Sirignano, "Droplet vaporization model for spray combustion calculations", Int. j. Heat Mass Transfer. Vol. 32, No. 9, pp. 1605-1618, 1988.

Boutabaa et al. "Numerical study of Dean vortices in developing Newtonian and viscoelastic flows through a curved duct of square cross-section", C. R. Mecanique, Vol. $337,2009$.

Chaker et al. " Inlet fogging of gas turbine engines- Part A: Fog droplet thermodynamics, heat transfer and practical considerations", Proceedings of ASME Turbo Expo 2002, 2002-GT-30562.

Chaker et al. "Inlet Fogging of Gas Turbine Engines-Part B: Fog Droplet Sizing Analysis, Nozzle Types, Measurement and Testing", Journal of Engineering for Gas Turbines and Power, Vol.126, No.3, pp.559-570, 2004.

Chaker et al. "Inlet Fogging of Gas Turbine Engines-Part C: Fog Behavior in Inlet Ducts, CFD Analysis and Wind Tunnel Experiments", Journal of Engineering for Gas Turbines and Power, Vol.126,No.3,pp. 571-580. 2004.

Collin, P. Boulet, G. Parent, and D. Lacroix, "Numerical simulation of a water sprayRadiation attenuation related to spray dynamics", Int. J. Therm. Sci., Vol. 46, No. 9, pp. 856-868, 2007.

Cable, "An Evaluation of Turbulence Models for the Numerical Study of Forced and Natural Convective Flow in Atria ", MS.C. Thesis, Queen's University, 2009.

Dean, "Fluid motion in a curved channel", Proceedings of the Royal Society of London. Series A, Vol.121, No.787, 1928.

Dutta et al. "Numerical study of curvature effect on turbulent flow in $90^{\circ}$ pipe bend" Proceedings of ICTACEM-2014/028.

Dutta et al. "Numerical Study on Turbulent Separation Reattachment Flow in Pipe Bends with Different Small Curvature Ratio", Journal of Institution of Engineers, India, 2018.

Hamandi et al. "Numerical simulation on droplet coalescence in an L-shaped duct for inlet fogging of gas turbine engines", International Journal of Gas Turbines, Propulsion and Power Systems, Vol.7, No.1, 2015. 
Mohammed, S. Abed-Alfathel, "The effect of curvature ratio on flow structure and fluids mixing in $90^{\circ}$ bent square duct", Journal of University of Babylon for Engineering Sciences, Vol.28, No.2, 2020.

Mohammed, S. Abed-Alfathel, "The effect of curvature ratio on the evaporative cooling of air flow through bent duct", Kufa Journal of Engineering, Vol.11,No.1, 2020.

Mohammed et al. "The effect of turbulences flow on a gas-liquid mixing process downstream of a curved duct", Journal of University of Babylon, Engineering Sciences, Vol.26, No.4, 2018.

Mondol et al. "Characteristics of gas flow through bend pipes of different angles", IOSR Journal of Mathematics, Vol.14, No.6, 2018.

Mon Soe and S. Yu Khaing, "Comparison of Turbulence Models for Computational Fluid Dynamics Simulation of Wind Flow on Cluster of Buildings in Mandalay," Int. J. Sci. Res. Publ., Vol. 7, No. 8, pp. 337-350, 2017.

Norouzi et al. "An analytical solution for Dean flow in curved ducts with rectangular cross section", Physics of Fluids, Vol.25, 2013.

Pratap et al. "Flow and heat transfer in curved duct", Ph.D. Thesis, Mechanical Engineering Department, London University, S.w. Vol.7, 1975.

Sudo et al., "Experimental investigation on turbulent flow in a circular-sectioned 90degree bend", Experiments in Fluids, Vol.25, 1998.

Shabani et al., "The effect of the pipe bending angle on the pressure losses vane elbow pipes", Asian Review of Civil Engineering, Vol.8, No.1, 2019.

Tilak et al. "Numerical prediction of secondary flow and convective heat transfer in externally heated curved rectangular ducts", International Journal of Thermal Sciences, Vol. 42, No. 2, 2003.

Thielicke, "PIVLAB - Towards user-friendly, affordable and accurate digital particle image velocimetry in MATLAB", Journal of Open Research Software, E, J 2014. 